Le Grange Daniel (Orcid ID: 0000-0001-7293-9496)

Hughes Elizabeth (Orcid ID: 0000-0002-4377-5610)

25

REMISSION IN FAMILY THERAPY

Variability in Remission in Family Therapy for Anorexia Nervosa

\author{
Daniel Le Grange ${ }^{1,4}$, Kathryn M Huryk ${ }^{2}$, Stuart B Murray ${ }^{1}$, Elizabeth K. Hughes ${ }^{3}$, Susan M. Sawyer ${ }^{3}$, \\ Katharine L. Loeb ${ }^{2}$ \\ ${ }^{1}$ University of California, San Francisco \\ ${ }^{2}$ Fairleigh Dickinson University \\ ${ }^{3}$ The University of Melbourne; Murdoch Children’s Research Institute; Royal Children’s Hospital \\ ${ }^{4}$ The University of Chicago (Emeritus)
}

Short Running Title: Remission in Family Therapy

Abstract word count: 250/250

Manuscript word count: 3,434/4,500

Funding, Acknowledgments, and Conflicts of Interest/Disclosure:

This research was supported by a grant from the Baker Foundation (Australia), which supported Drs. Le Grange and Hughes. The Murdoch Children’s Research Institute is supported by the Victorian Government’s Operational Infrastructure Support Program.

This is the author manuscript accepted for publication and has undergone full peer review but has not been through the copyediting, typesetting, pagination and proofreading process, which may lead to differences between this version and the Version of Record. Please cite this article as doi: $10.1002 /$ eat.23138

This article is protected by copyright. All rights reserved. 
Disclosures: Dr. Loeb receives royalties from Routledge, and is a faculty member of and consultant for the Training Institute for Child and Adolescent Eating Disorders. Dr. Murray receives royalties from Routledge, and Oxford University Press. Dr. Le Grange receives royalties from Guilford Press and Routledge, and is co-director of the Training Institute for Child and Adolescent Eating Disorders, LLC.

Key words: anorexia nervosa, adolescents, family-based treatment, treatment outcome, remission

Article Correspondence: Daniel Le Grange, Department of Psychiatry, University of California, San

Francisco. 401 Parnassus Avenue, Box F-0984, LPPI Room 368.

Phone: 415-502-2627. Email: Daniel.legrange@ucsf.edu

This article is protected by copyright. All rights reserved. 


\begin{abstract}
Objective: The evolution toward more stringent conceptualizations of remission in family therapy for adolescent anorexia nervosa (AN) has, with time, introduced variability in outcomes across randomized controlled trials (RCTs). An examination of remission across the history of research on family therapy for AN shows that earlier studies adopted lenient definitions and generally yielded higher rates of remission than studies of the past decade that have used stricter definitions of remission. In this study, we investigate the reactivity of remission rates to the application of different definitions of remission used within the family therapy for AN literature, within a single RCT dataset.
\end{abstract}

Method: We conducted a secondary analysis of data from a single-site RCT which compared the relative efficacy of two formats of family therapy in a sample of 106 Australian adolescents with AN. Using end-of-treatment data, we compared remission rates using 11 definitions of remission that have been used in studies of family therapy for AN spanning more than three decades.

Results: We found wide variability in remission rates $\left[21.7 \%\right.$ to $87.7 \%$; Cochran's $\mathrm{Q} \chi^{2}(10, \mathrm{~N}=106)=$ 303.55, $p=.000$ ], depending on which definition of remission was applied. As expected, more lenient criteria produced higher remission rates than more stringent definitions.

Discussion: Applying different criteria of remission to a single dataset illustrates the impact of changing how remission is defined. Failure to consider the greater stringency of remission criteria in recent studies could result in false inferences concerning the efficacy of family therapy for AN over time. 


\section{Variability in Remission in Family Therapy for Anorexia Nervosa}

For more than fifty years, anorexia nervosa (AN) has been the focus of a series of family therapy interventions designed to facilitate remission by targeting family-level processes. Family-based treatment (FBT; Lock \& Le Grange, 2013) is an intervention that is currently considered the first-line treatment for medically stable adolescents with AN (National Institute for Health and Care Excellence [NICE], 2017). The treatment outcome literature on FBT has recently been synthesized in both a metaanalysis and comprehensive review (Couturier, Kimber, \& Szatmari, 2013; Lock \& Le Grange, 2018), each illustrating the relative efficacy of FBT compared to other psychological interventions for eating disorders in children and adolescents. Notably, there was marked variability across these studies in the outcome variables used to test the efficacy of FBT. In this paper, we examine rates of remission across the history of research on family therapy for AN (i.e., within-treatment change), rather than in contrast to other interventions. We also investigate the reactivity of remission rates to the application of various definitions of remission that have been used to delineate treatment response in FBT research.

Early treatment studies (Eisler et al., 2000; Russell, Szmukler, Dare, \& Eisler, 1987) defined outcomes primarily as a function of weight status. Embedded within the psychopathology of AN, emaciation represents a cardinal sign of illness. Low body weight is clinically significant in its own right and often portends an array of medical complications, including cardiac abnormalities and amenorrhea (Mehler \& Brown, 2015); it is also an obstacle to change and a driver of cognitive symptoms, i.e., fear of weight gain, drive for thinness (Accurso, Ciao, Fitzsimmons-Craft, Lock, \& Le Grange, 2014). Reversing the state of starvation is therefore a priority in any intervention for AN. To this end, weight 
measurements are a key indicator of treatment response, even when cognitive remission lags behind physical remission (Murray, Quintana, Loeb, Griffiths, \& Le Grange, 2019). Moreover, weight measures have the added benefit of being relatively objective in comparison to the self-reported cognitive features of AN, particularly for adolescents (Bravender et al., 2010).

Despite the importance of weight-based outcomes, this narrow measure has been reconsidered over time within wider questioning in the field regarding how to optimally operationalize AN recovery, a construct that goes beyond remission in scope and duration (Bardone-Cone et al., 2010; Couturier \& Lock, 2006a; Dawson, Rhodes, \& Touyz, 2015). Given the fragility of partial clinical improvement (Khalsa, Portnoff, McCurdy-McKinnon, \& Feusner, 2017), and the high risk of chronicity in AN (Eddy et al., 2017; Fichter, Quadflieg, Crosby, \& Koch, 2017; Herpertz-Dahlmann et al., 2018), it has been argued that the bar for clinical efficacy in AN RCTs should be set high. In this earnest effort, aptly highlighted by Bardone-Cone and her colleagues (2018), the broader eating disorder community is urged to reach consensus on how to define recovery, and that this definition includes at least three key criteria; physical, behavioral, and psychological well-being. Presently, however, there is still no consensus as to precisely what constitutes clinically significant change over a course of treatment for AN.

\section{Definitions and Rates of Remission in Family Interventions for AN}

Fourteen RCTs of family therapy for adolescent AN and four corresponding longer-term followup studies have been published to date. This includes the earliest trials of family therapy for adolescent AN (FT-AN) from which FBT derives (Lock \& Le Grange, 2013). Table 1 summarizes the definitions and rates of remission described in each of these studies, apart from two in which remission rates were 
not reported as outcomes (Geist, Heinman, Stephens, Davis, \& Katzman, 2000; Lock, Fitzpatrick, Agras, Weinbach, \& Jo, 2018). Across these studies, rates of remission at end-of-treatment and followup varied from $21 \%$ to $96 \%$. Notably, remission rates in earlier studies (1987 - 2006) ranged from $47 \%$ to $96 \%$, while remission rates from the past decade (2010 - 2016) have ranged from $21 \%$ to $78 \%$. This raises the possibility that more recent studies have less positive results.

\section{[Insert Table 1 about here]}

In studies of FT-AN, remission was measured with the Morgan-Russell outcome scale, a semistructured interview that assesses weight, menstrual status, mental status, psychosocial and psychosexual development, as well as binge eating or purging behavior. Cognitive symptoms are not directly evaluated. "Good” plus “intermediate” outcomes are considered to be treatment success as compared to “poor” outcome (Morgan \& Hayward, 1988; Morgan \& Russell, 1975; Russell et al., 1987). Applying this scale in a somewhat redacted format, patients achieve "good" outcome when they maintain their weight above $85 \% \mathrm{mBMI}^{\mathrm{a}}$ (median body mass index), have no binge eating or purging behavior, and menstruate (for postmenarchal females). "Intermediate” outcome involves the same weight criterion, but patients are either not menstruating or experiencing bulimic symptoms on an average of less than once per week over the past month. Patients are described as having "poor" outcome when their weight is less than $85 \%$ mBMI or they experience more frequent bulimic symptoms. Thus, using the Morgan Russell scale, allows one to meet criteria for remission (i.e., "good” + "intermediate” outcome) by having a body

${ }^{\text {a }}$ The preferred terms used to define and describe weight status within the ED field have changed over time, previously including ideal and expected body weight (IBW and EBW, respectively). Currently, percent median body mass index (\% mBMI) is the recommended standard, and is calculated as (current $\mathrm{BMI} / 50^{\text {th }}$ percentile BMI for age and sex) x 100 (Golden, Katzman, Sawyer, \& Ornstein, 2015). 
weight $\geq 85 \% \mathrm{mBMI}$ with bulimic symptoms occurring on average less than once per week over the past month.

Studies using the Morgan-Russell scale have reported remission rates ranging from $47 \%$ to $90 \%$ (Ball \& Mitchell, 2004; Eisler et al., 2000; Eisler et al., 1997; Eisler et al., 2016; Eisler, Simic, Russell, \& Dare, 2007; Le Grange, Eisler, Dare, \& Russell, 1992; Russell et al., 1987). Likewise, other early studies (Lock, Agras, Bryson, \& Kraemer, 2005; Robin et al., 1999) placed an emphasis on weight restoration, yet defined remission using relatively low body mass index (BMI) or BMI percentile cutoffs (e.g., BMI $>17.5, \mathrm{BMI} \geq 25^{\text {th }}$ percentile for age ${ }^{\mathrm{b}}$ ). Such operational definitions do not set high expectations for remission, as patients can be considered remitted despite relatively low weight , the presence of broader disordered eating behaviors (i.e., bulimic symptoms), and the persistence of cognitive AN psychopathology (i.e., ongoing fear of weight gain, drive for thinness).

Recent studies have used more rigorous definitions of remission. First, the more conservative threshold of $\geq 95 \% \mathrm{mBMI}$ is now commonly used to delineate weight restoration (Agras et al., 2014; Le Grange et al., 2014; Le Grange et al., 2016; Lock et al., 2010; Lock et al., 2015; Madden et al., 2015b), given evidence that this threshold best predicts longer-term recovery for adolescents with AN (Accurso et al., 2014; Lock et al., 2013). In FBT studies using this higher threshold, reported rates of remission range from 33\% to 63\% (Agras et al., 2014; Lock et al., 2015). Second, beginning with Lock et al. (2005), studies have frequently incorporated the Eating Disorder Examination (EDE) (Fairburn, Cooper, \& O’Connor, 2014) to assess change of cognitive and behavioral symptoms of AN over the course of

\footnotetext{
${ }^{\mathrm{b}}$ BMI percentile for age was calculated using the standardized growth charts available at that time (US Department of Health, Education, and Welfare, 1973).
} 
FBT. Although the EDE assesses frequency of bulimic symptoms, these particular behavioral data are not incorporated in the EDE Global score. In combining weight and cognitive symptoms, remission has been defined as $\geq 95 \%$ mBMI plus EDE Global score within one standard deviation (SD) of community norms ( $\leq 1.59$ ) (Fairburn \& Beglin, 1994). Lock and Le Grange were the first to employ this combined criterion set in a multi-site RCT that compared FBT to adolescent-focused individual therapy (Lock et al., 2010). When using this strict definition of combined weight and cognitive remission, rates of remission in studies of FBT have ranged from 21\% to 43\% (Le Grange et al., 2014; Le Grange et al., 2016; Lock et al., 2010; Madden et al., 2015b). A similar definition that uses the same weight cutoff, but an EDE global score within 2 SDs of community norms $(\leq 2.52)$, has been applied in some studies (Lock, Couturier, Bryson, \& Agras, 2006; Madden et al., 2015a). However, this definition has not been reported as a main outcome in randomized studies of FBT.

An early study by Couturier and Lock (2006b) applied various definitions from a broad body of adult and adolescent AN literature to a FBT RCT dataset, illustrating their respective impact on remission. Since that paper was published, the number of FBT RCTs has doubled, bringing with it additional criteria sets for remission. For instance, in one later RCT (Madden et al., 2015a), the authors demonstrated outcome variability as a function of two different definitions of remission. However, no study to date has applied the full range of definitions of remission from three decades of FBT RCT literature to one recent FBT RCT sample. Elucidating definitional shifts in FBT-AN outcomes, and the corresponding implications for interpreting the past and recent FBT literature, would promote transparency around the evidence-base for this intervention. It may also help establish future research 
priorities, such as a more direct, rapid, and targeted amelioration of cognitive symptoms in parallel to weight restoration (Murray, Loeb, \& Le Grange, 2018; Murray et al., 2019).

The evolving definition of remission is one factor that has potentially contributed to the wide variability in remission rates reported across studies of family therapy, with an apparent trend toward declining outcomes over the past 30 years. To formally investigate the reactivity of remission rates to various definitions of remission used in the AN family therapy literature, we conducted a secondary analysis of an RCT that compared two formats of FBT (Le Grange et al., 2016). Specifically, the present study aimed to explicate if and how the definition of remission affects reported outcomes, a crucial endeavor in parsing out the efficacy of this intervention across its history. We hypothesized there would be significant variability in the derived remission rates, with definitions using weight only, low weight thresholds and/or no amelioration of cognitive or behavioral symptoms, yielding higher remission rates compared to definitions requiring higher thresholds on these parameters.

\section{Method}

Data for this secondary analysis were derived from a single-site RCT from Melbourne, Australia which compared the relative efficacy of conjoint FBT and parent-focused treatment (PFT), a separatedformat variant of FBT (Le Grange et al., 2016). The data that support the findings of this study are available from the corresponding author upon reasonable request. For the purpose of this analysis, we combined the full sample of the RCT rather than separating the two conditions. Specifically, conjoint FBT and PFT are variants of the same core intervention; our goal was not to parse out differential 
responses to treatment among the multiple versions of family therapy for AN, nor to perform a reanalysis of the primary outcome in the main study hypotheses.

Participants were 106 adolescents $(M=15.5, S D=1.5)$ who met a DSM-IV diagnosis of AN with two modifications in alignment with the proposed diagnostic criteria for AN within DSM-5, which had an anticipated publication timeline during the course of this RCT. As reported in the main outcome manuscript (Le Grange et al., 2016), the study did not apply the amenorrhea criterion and applied greater flexibility in operationalizing low weight status, i.e., $\leq 90 \% \mathrm{mBMI}$ for adolescents $\leq 75^{\text {th }}$ percentile for height, and $<95 \%$ mBMI for adolescents $\geq 75^{\text {th }}$ percentile for height. At baseline, participants’ mean \%mBMI was $81.9(S D=6.1)$, and mean duration of illness was 10.5 months $(S D=8.8$, range 2-48 months). There were no significant baseline differences between treatment groups; detailed demographic and clinical characteristics have been reported elsewhere (Le Grange et al., 2016).

Using end-of-treatment data from this RCT, we recalculated remission rates for the entire study sample using the definitions commonly reported in all prior studies of FT-AN and FBT across the past 30 years. Based on this literature, remission was evaluated with 11 definitions, summarized in Table 2. In the RCT dataset (used in the current analysis), for cases where there were missing EDE data at endof-treatment ( $n=13)$, the imputed value for the EDE Global score based upon multiple imputation (c.f., Le Grange et al., 2016) was applied in determining remission status. Because the Morgan Russell Scale was not administered to the Melbourne dataset, we reconstructed this scale’s remission criteria from extracted items on the EDE. In the event that bulimic symptom data were missing $(n=12)$, a 
conservative approach was taken and the participant was considered not remitted. Variability in rates of remission across definitions was tested using the non-parametric Cochran's Q test for related samples.

\section{Results}

In calculating data for these 106 adolescents using BMI and BMI percentile cutoffs from the extant literature reviewed, the following remission rates were obtained: 76.4\% (81) for BMI > 17.5, $59.4 \%$ (63) for $\mathrm{BMI} \geq 25^{\text {th }}$ percentile for age, and $21.7 \%$ (23) for BMI $\geq 50^{\text {th }}$ percentile for age. Using varying \%mBMI cutoffs, the following remission rates were generated: $75.5 \%$ (80) at $\geq 85 \% \mathrm{mBMI}$, 61.3\% (65) at $\geq 90 \% \mathrm{mBMI}$, and 42.5\% (45) at $\geq 95 \%$ mBMI. Applying the Morgan Russell Scale produced a remission rate of 58.5\% (62 of 106); excluding those with missing bulimic symptom data produced a remission rate of $66 \%(62 \text { of } 94)^{\mathrm{c}}$ (See Figure 1$)$.

When remission was defined in the 106 cases using EDE Global scores alone, the following remission rates were obtained: $87.7 \%$ at EDE Global within 2 SDs of community norms, and $77.4 \%$ at EDE Global within 1 SD of community norms. Combining weight status with the EDE yielded the following rates of remission: 37.7\% $\geq 95 \%$ mBMI plus EDE Global within 2 SDs of norms, and 32.1\% $\geq 95 \%$ mBMI plus EDE Global within 1 SD of norms. Cochran’s Q test for related samples was significant $\left[\chi^{2}(10, \mathrm{~N}=106)=303.55, p=.000\right]$.

[Insert Table 2 and Figure 1 about here]

'Of 106 participants, 13 were missing each of the bulimic symptom items on the EDE (e.g., frequency of objective binging, self-induced vomiting, laxative misuse, and driven exercise). Of those 13: 1 was also missing weight, 5 were below 85\% mBMI, and 7 were above 85\% mBMI. Hypothetically, if each of these 7 individuals did not have bulimic symptoms, 65\% of the sample would have been considered remitted. 


\section{Discussion}

Exploring the reactivity of remission rates to the application of various criteria that have been used to define treatment response in AN family treatment research confirmed a broad range of statistically distinct remission rates within a single dataset. These outcomes can be consolidated into three categories. First, when the definition of remission incorporated only weight status, with the threshold set low (e.g., BMI > 17.5 or $\geq 85 \% \mathrm{mBMI}$ ), or only cognitive remission, as represented by an EDE Global score within one or two SDs of community norms, remission was achieved by a majority of patients ( $>75 \%$ on average). Second, when the weight threshold was set higher (e.g., BMI $\geq 25^{\text {th }}$ percentile, or at least 90\%mBMI), or using the Morgan Russell Scale “good” plus “intermediate” categories, the remission rate was approximately 60\%. The third definition used a high weight threshold with a BMI > 50th percentile, or minimum 95\%mBMI, or the latter weight threshold with the EDE Global score within one or two SDs of community norms, but did not include behavioral criteria (i.e., binge eating/purging). Remission was achieved in about one third of patients. The RCT from which these secondary analyses were undertaken applied this latter definition of remission and correspondingly found that about one third of patients achieved remission at end-of-treatment (Le Grange et al., 2016). The consequence of changing the definition of remission is clearly demonstrated; if any of the first definition criteria were applied to this RCT sample, remission rates would have appeared similar to those in the earlier family therapy studies (e. g. Eisler et al., 2000; Russell et al., 1987). Or to put it slightly differently, remission rates in the most recently published RCT for family therapy would have been above 80\%, that is, identical to that in the seminal study published in 1987 (Russell et al., 1987). 
While implications of variable definitions of remission for research are apparent, implications for clinical care are also clear. For example, if clinicians decide to terminate treatment of adolescents with AN based only on when these patients meet remission criteria that sets a low bar (e.g., low weight cutoff), discharge from care could be premature and put their patients at greater risk of relapse.

Our results, together with those of Couturier and Lock (2006b) and Madden and his colleagues (2015a), illustrate that stricter definitions of remission are generally associated with lower remission rates. The evolution toward conceptualizations of outcomes of FBT where thresholds are high is a positive trend as it ensures that treatment efficacy is not overstated. Certainly, if one accepts the notion that cognitive factors propel the weight loss characteristic of $\mathrm{AN}$, then determining remission as a function of both cognitive and weight-related symptoms is necessary. However, the evolution of the conceptualization of treatment outcomes, by definition, has introduced variability in the intervention over time and across RCTs, regardless of other changes. As a result, outcomes in FBT could appear to be worsening over time - under the assumption of an "apples to apples” rather than "apples to oranges” set of comparisons - even as manualization and implementation of this treatment have been considerably refined during this period (Couturier \& Kimber, 2015; Lock \& Le Grange, 2013). As such, the risk is that treatment efficacy may be understated when higher thresholds for remission are applied. This is particularly significant as newer adaptations of FBT (e.g., varying delivery format) that utilize outcome criteria that include both weight and cognitive recovery are being carefully scrutinized for their efficacy. Understanding the implications of different definitions of remission are critical to ensure that appropriate comparisons are made. A failure to consider the greater stringency of these later remission 
criteria could result in false inferences concerning the execution and efficacy of family therapy over time and across investigators.

Our study raises at least two questions for consideration; (1) do the findings challenge the purported efficacy of FBT, and (2) can these findings inform consensus on a core outcome set for eating disorders, as promulgated by the COMET initiative (Core Outcome Measures in Effectiveness Trials (http://www.comet-initiative.org)? In addressing the first questions, it is important to note that the current study was not designed to empirically identify the best measure of efficacy of FBT, or directly address the efficacy of FBT. That said, our findings help explain, rather than challenge the purported efficacy of FBT. Going forward, there is a need for research which examines the reliability, construct validity, and predictive validity of the various definitions of remission to inform such recommendations (c.f., Lock et al., 2013; Madden et al., 2015a). This would in turn assist in addressing the second question, which is to consider what constitutes the core outcome definition, as endorsed by COMET, that should be reported for future efficacy trials in adolescent AN. We not only argue for agreement in the field for a uniform approach to reporting remission, but also advocate for a definition of remission that, at a minimum, should strive to set the bar for (1) weight status at a level that would support growth, bone health, hormonal functioning, and cognitive development in adolescents (e.g., $\geq 95 \% \mathrm{mBMI}$ ), and (2) eating- and body-related cognitive, as well as (3) behavioral status at levels that reflect normal development (e.g., EDE Global Score within 1 SD of the community norm and an absence of binge eating or purging). Venturing to suggest a definition of remission that can be applied transdiagnostically and across age groups, while much needed, is outside the scope of this manuscript. 
Findings from the current study offer important insights into the potential challenges of betweentrial comparisons across studies which utilize different conceptualizations of outcomes in the treatment of AN. Appropriate attention to such detail is urged whether interpreting individual study results or findings across the AN treatment literature, or when utilizing such information to inform clinical care. Our findings also have implications for the broader eating disorder treatment outcome literature in that there are as many definitions of remission as there are published studies, regardless of diagnosis (Bardone-Cone et al., 2018). Gaining consensus in this broader field about the definition of remission is of critical importance in prospectively creating a cohesive storyline as this body of research evolves. 


\section{References}

Accurso, E. C., Ciao, A. C., Fitzsimmons-Craft, E. E., Lock, J. D., \& Le Grange, D. (2014). Is weight gain really a catalyst for broader recovery? The impact of weight gain on psychological symptoms in the treatment of adolescent anorexia nervosa. Behavioral Research and Therapy, 56, 1-6. doi: 10.1016/j.brat.2014.02.006

Agras, W. S., Lock, J., Brandt, H., Bryson, D. W., Dodge, E., Halmi, K. A., ...Woodside, B. (2014). Comparison of 2 family therapies for adolescent anorexia nervosa: A randomized parallel trial. JAMA Psychiatry, 71(11), 1279-1286. doi: 10.1001/jamapsychiatry.2014.1025

Ball, J., \& Mitchell, P. (2004). A randomized controlled study of cognitive behavior therapy and behavioral family therapy for anorexia nervosa patients. Eating Disorders, 12(4), 303-314. doi: 10.1080/10640260490521389

Bardone-Cone, A. M., Harney, M. B., Maldonado, C. R., Lawson, M., Robinson, D. P., Smith, R., \& Tosh, A. (2010). Defining recovery from an eating disorder: Conceptualization, validation, and examination of psychosocial functioning and psychiatric comorbidity. Behavior Research and Therapy, 48(3), 194-202. doi: 10.1016/j.brat.2009.11.001

Bardone-Cone, A. M., Hunt, R. A., \& Watson, H. J. (2018). An overview of conceptualizations of eating disorder recovery, recent findings, and future directions. Current Psychiatry Reports, 20, 79. doi: 10.1007/s11920-018-0932-9

This article is protected by copyright. All rights reserved. 
Bravender, T., Bryan-Waugh, R., Herzog, D., Katzman, D., Kriepe, R. D., Lask, B...Zucker, N. (2010). Classification of eating disturbance in children and adolescents: proposed changes for the DSMV. European Eating Disorders Review, 18(2), 79-89. doi: 10.1002/erv.994

Couturier, J. L., \& Kimber, M. S. (2015). Dissemination and implementation of manualized familybased treatment: A systematic review. Eating Disorders, 23(4), 281-290. doi: 10.1080/10640266.2015.1042312

Couturier, J., Kimber, M., \& Szatmari, P. (2013). Efficacy of family-based treatment for adolescents with eating disorders: A systematic review and meta-analysis. International Journal of Eating Disorders, 46(1), 3-11. doi: 10.1002/eat.22042

Couturier, J., \& Lock, J. (2006a). What is recovery in adolescent anorexia nervosa? International Journal of Eating Disorders, 39(7), 550-555. doi: 10.1002/eat.20309

Couturier, J., \& Lock, J. (2006b). What is remission in adolescent anorexia nervosa? A review of various conceptualizations and quantitative analysis. International Journal of Eating Disorders, 39(3), 175-183. doi: 10.1002/eat.20224

Dawson, L., Rhodes, P., \& Touyz, S. (2015). Defining recovery from anorexia nervosa: A Delphi study to determine expert practitioners’ views. Advances in Eating Disorders: Theory, Research, and Practice, 3(2), 165-176. doi: 10.1080/21662630.2015.1009145

Eddy, K. T., Tabri, N., Thomas, J. J., Murray, H. B., Keshaviah, A., Hastings, E...Franko, D. L. (2017). Recovery from anorexia nervosa and bulimia nervosa at 22-year follow-up. Journal of Clinical Psychiatry, 78(2), 184-189. doi: 10.4088/JCP.15m10393.

This article is protected by copyright. All rights reserved. 
Eisler, I., Dare, C., Hodes, M., Russell, G., Dodge, E., \& Le Grange, D. (2000). Family therapy for adolescent anorexia nervosa: The results of a controlled comparison of two family interventions. Journal of Child Psychology and Psychiatry, 41(6), 727-736. doi: 10.1111/1469-7610.00660

Eisler, I., Dare, C., Russell, G. F. M., Szmukler, G., Le Grange, D., \& Dodge, E. (1997). Family and individual therapy in anorexia nervosa. A 5-year follow-up. Archives of General Psychiatry, 54(11), 1025-1030. doi:10.1001/archpsyc.1997.01830230063008

Eisler, I., Simic, M., Hodsoll, J., Asen, E., Berelowitz, M., Connan, F...Landau, S. (2016). A pragmatic randomised multi-centre trial of multifamily and single family therapy for adolescent anorexia nervosa. BMC Psychiatry, 16(1), 422. doi: 10.1186/s12888-016-1129-6

Eisler, I., Simic, M., Russell, G. F. M., \& Dare, C. (2007). A randomised controlled treatment trial of two forms of family therapy in adolescent anorexia nervosa: a five-year follow-up. The Journal of Child Psychology and Psychiatry, 48(6), 552-560. doi: 10.1111/j.1469-7610.2007.01726.x

Fairburn, C. G., \& Beglin, S. J. (1994). Assessment of eating disorders: Interview or self-report questionnaire? International Journal of Eating Disorders, 16(4), 363-370. doi: 10.1002/1098108X(199412)16:4<363:AID-EAT2260160405>3.0.CO;2-\%23

Fairburn C. G., Cooper, Z., \& O’Connor, M. (2014). Eating Disorder Examination, Edition 17.0D. The Center for Research on Dissemination at Oxford. Retrieved from http://www.credooxford.com/pdfs/EDE_17.0D.pdf.

This article is protected by copyright. All rights reserved. 
Fichter, M. M., Quadflieg, N., Crosby, R. D., \& Koch, S. (2017). Long-term outcome of anorexia nervosa: Results from a large clinical longitudinal study. International Journal of Eating Disorders, 50(9), 1018-1030. doi: 10.1002/eat.22736.

Geist, R., Heinmaa, M., Stephens, D., Davis, R., \& Katzman, D. K. (2000). Comparison of family therapy and family group psychoeducation in adolescents with anorexia nervosa. Canadian Journal of Psychiatry, 45(2), 173-178. doi: 10.1177/070674370004500208

Golden, N. H., Katzman, D. K., Sawyer, S. M., \& Ornstein, R. M. (2015). Position paper of The Society for Adolescent Health and Medicine: Medical management of restrictive eating disorders in adolescents and young adults. Journal of Adolescent Health, 56(1), 121-125. doi: 10.1016/j.jadohealth.2014.10.259.

Herpetz-Dahlmann, B., Dempfle, A., Egberts, K. M., Kappel, V., Konrad, K., Vloet, J. A., \& Buhren, K. (2018). Outcome of childhood anorexia nervosa - The results of a five- to ten-year follow-up study. International Journal of Eating Disorders, 51(4), 295-304. doi: 10.1002/eat.22840

Khalsa, S. S., Portnoff, L. C., McCurdy-McKinnon, D., \& Feusner, J. D. (2017). What happens after treatment? A systematic review of relapse, remission, and recovery in anorexia nervosa. Journal of Eating Disorders, 5(1), 20. doi: 10.1186/s40337-017-0145-3

Le Grange, D., Eisler, I., Dare, C., \& Russell, G. F. M. (1992). Evaluation of family treatments in adolescent anorexia nervosa: A pilot study. International Journal of Eating Disorders, 12(4), 347-357. doi: 10.1002/1098-108X(199212)12:4<347:AID-EAT2260120402>3.0.CO;2-W

This article is protected by copyright. All rights reserved. 
Le Grange, D., Hughes, E. K., Court, A., Yeo, M., Crosby, R. D., \& Sawyer, S. M. (2016). Randomized clinical trial of parent-focused treatment and family-based treatment for adolescent anorexia nervosa. Journal of the American Academy of Child and Adolescent Psychiatry, 55(8), 683-692. doi: 10.1016/j.jaac.2016.05.007.

Le Grange, D., Lock, J., Accurso, E. C., Agras, W. S., Darcy, A., Forsberg, S., \& Bryson, S. W. (2014). Relapse from remission at two- to four-year follow-up in two treatments for adolescent anorexia nervosa. Journal of the American Academy of Child and Adolescent Psychiatry, 53(11), 11621167. doi: 10.1016/j.jaac.2014.07.014

Lock, J., Agras, W. S., Bryson, S., \& Kraemer, H. C. (2005). A comparison of short- and long-term family therapy for adolescent anorexia nervosa. Journal of the American Academy of Child and Adolescent Psychiatry, 44(7), 632-639. doi: 10.1097/01.chi.0000161647.82775.0a

Lock, J., Agras, W. S., Le Grange, D., Couturier, J., Safer, D., \& Bryson, S. W. (2013). Do end of treatment assessments predict outcome at follow-up in eating disorders? International Journal of Eating Disorders, 46(8), 771-778. doi: 10.1002/eat.22175.

Lock, J., Couturier, J., \& Agras, W. S. (2006). Comparison of long-term outcomes in adolescents with anorexia nervosa treated with family therapy. Journal of the American Academy of Child and Adolescent Psychiatry, 45(6), 666-672. doi: 10.1097/01.chi.0000215152.61400.ca

Lock, J., Couturier, J., Bryson, S., \& Agras, S. (2006). Predictors of dropout and remission in family therapy for adolescent anorexia nervosa in a randomized clinical trial. International Journal of Eating Disorders, 39(8), 639-647. doi: 10.1002/eat.20328

This article is protected by copyright. All rights reserved. 
Lock, J., Fitzpatrick, K. K., Agras, W. S., Weinbach, N., \& Jo, B. (2018). Feasibility study combining art therapy and cognitive remediation therapy with family-based treatment for adolescent anorexia nervosa. European Eating Disorders Review, 26(1), 62-68. doi: 10.1002/erv.2571.

Lock, J., \& Le Grange, D. (2013). Treatment manual for anorexia nervosa: A family-based approach (2nd ed.). New York, NY: Guilford Press.

Lock, J., \& Le Grange, D. (2018). Family-based treatment: Where are we and where should we be going to improve recovery in child and adolescent eating disorders? International Journal of Eating Disorders. doi:10.1002/eat.22980.

Lock, J., Le Grange, D., Agras, W. S., Fitzpatrick, K. K., Jo, B., Accurso, E...Stainer, M. (2015). Can adaptive treatment improve outcomes in family-based therapy for adolescents with anorexia nervosa? Feasibility and treatment effects of a multi-site treatment study. Behavior Research and Therapy, 73, 90-95. doi: 10.1016/j.brat.2015.07.015.

Lock, J., Le Grange, D., Agras, W., Moye, A., Bryson, S. W., \& Jo, B. (2010). Randomized clinical trial comparing family-based treatment with adolescent-focused individual therapy for adolescents with anorexia nervosa. Archives of General Psychiatry, 67(10), 1025-1032. doi:

10.1001/archgenpsychiatry.2010.128

Madden, S., Miskovic-Wheatley, J., Wallis, A., Kohn, M., Hay, P., \& Touyz, S. (2015a). Early weight gain in family-based treatment predicts greater weight gain and remission at the end of treatment and remission at 12-month follow-up in adolescent anorexia nervosa. International Journal of Eating Disorders, 48(7), 919-922. doi: 10.1002/eat.22414

This article is protected by copyright. All rights reserved. 
Madden, S., Miskovic-Wheatley, J., Wallis, A., Kohn, M., Lock, J., \& Le Grange, D...Touyz, S. (2015b). A randomized controlled trial of in-patient treatment for anorexia nervosa in medically unstable adolescents. Psychological Medicine, 45(2), 415-427. doi: 10.1017/S0033291714001573.

Mehler, P. S., \& Brown, C. (2015). Anorexia nervosa - medical complications. Journal of Eating Disorders, 3(1), 11. doi: 10.1186/s40337-015-0040-8

Morgan, H. G., \& Hayward, A. E. (1988). Clinical assessment of anorexia nervosa: The Morgan-Russell outcome assessment schedule. The British Journal of Psychiatry, 152, 367-371. doi: 10.1192/bjp.152.3.367

Morgan, H. G., \& Russell, G, F. M. (1975). Value of family background and clinical features as predictors of long-term outcome in anorexia nervosa: four-year follow-up study of 41 patients. Psychological Medicine, 5(4), 355-371. doi: 10.1017/S0033291700056981

Murray S. B., Loeb K. L., Le Grange D. (2018). Treatment outcome reporting in anorexia nervosa: time for a paradigm shift? Journal of Eating Disorders, 6:10. PMID: 29760916.

Murray, S. B., Quintana, D. S., Loeb, K. L., Griffiths, S., \& Le Grange, D. (2019). Treatment outcomes for anorexia nervosa: A systematic review and meta-analysis of randomized controlled trials. Psychological Medicine, 49(4), 535-544. doi: 10.1017/S0033291718002088.

National Institute for Health Care and Excellence. (2017). Eating disorders: Recognition and treatment (NICE guideline NH69). Retrieved from: https://www.nice.org.uk/guidance/ng69 
Robin, A. L., Siegel, P. T., Moye, A. W., Gilroy, M., Dennis, A. B., \& Sikand, A. (1999). Controlled comparison of family versus individual therapy for adolescents with anorexia nervosa. Journal of the American Academy of Child and Adolescent Psychiatry, 38(12), 1482-1489. doi: 10.1097/00004583-199912000-00008 •

Russell, G. F., Szmukler, G. I., Dare, C., \& Eisler, I. (1987). An evaluation of family therapy in anorexia nervosa and bulimia nervosa. Archives of General Psychiatry, 44(12), 1047-1056. doi: 10.1001/archpsyc.1987.01800240021004

US Department of Health, Education and Welfare (1973). Height and weight of youths 12-17 years (DHEW Publication HSM 73-1608). Washington, DC: US Government Printing Office. 
Table 1: Definitions and rates of remission at end-of-treatment and follow-up in randomized clinical trials of family interventions for adolescent anorexia nervosa.

\begin{tabular}{|c|c|c|c|c|}
\hline Study & $\begin{array}{c}\text { Sample } \\
\text { Characteristics }\end{array}$ & Definition of Remission & Treatment Component & \% Remitted \\
\hline \multirow{2}{*}{$\begin{array}{l}\text { Russell et al. } \\
1987 \& \\
\text { Eisler et al. } \\
1997\end{array}$} & \multirow{2}{*}{$\begin{array}{l}n=10^{\mathrm{a}} \\
100 \% \text { female } \\
12-18 \text { years } \\
<3 \text { years duration AN }\end{array}$} & \multirow[t]{2}{*}{$\begin{array}{l}\text { "good” or “intermediate” Morgan } \\
\text { Russell Scale (MRS) }\end{array}$} & Family Therapy (FT) & 90 \\
\hline & & & FT (5 years) & 90 \\
\hline $\begin{array}{l}\text { Le Grange et } \\
\text { al. } 1992\end{array}$ & $\begin{array}{l}N=18 \\
89 \% \text { female } \\
12-17 \text { years } \\
<3 \text { years duration } \mathrm{AN}\end{array}$ & “good” or “intermediate” MRS & FT or Family Counseling (FC) & 67 \\
\hline \multirow[t]{6}{*}{$\begin{array}{l}\text { Robin et al. } \\
1999\end{array}$} & \multirow{6}{*}{$\begin{array}{l}n=19 \\
100 \% \text { female } \\
11-20 \text { years }\end{array}$} & \multirow[t]{2}{*}{$\begin{array}{l}\text { attainment of target weight established } \\
\text { by pediatrician }\end{array}$} & $\begin{array}{l}\text { Behavioral Family Systems } \\
\text { Therapy (BFST) }\end{array}$ & 67 \\
\hline & & & BFST (12 months) & 80 \\
\hline & & \multirow{2}{*}{$\begin{array}{l}25^{\text {th }} \text { percentile of Body Mass Index } \\
\text { (BMI) for age }\end{array}$} & BFST & 84 \\
\hline & & & BFST (12 months) & 87 \\
\hline & & \multirow[t]{2}{*}{$50^{\text {th }}$ percentile of BMI for age } & BFST & 53 \\
\hline & & & BFST (12 months) & 67 \\
\hline \multirow{4}{*}{$\begin{array}{l}\text { Eisler et al. } \\
2000 \& \\
\text { Eisler et al. } \\
2007\end{array}$} & \multirow{4}{*}{$\begin{array}{l}N=40 \\
98 \% \text { female } \\
11-17 \text { years }\end{array}$} & \multirow[t]{4}{*}{ “good” or “intermediate” MRS } & Conjoint FT & 47 \\
\hline & & & Conjoint FT (5 years) & 78 \\
\hline & & & Separated FT & 76 \\
\hline & & & Separated FT (5 years) & 90 \\
\hline \multirow[t]{2}{*}{$\begin{array}{l}\text { Ball \& } \\
\text { Mitchell } 2004\end{array}$} & \multirow{2}{*}{$\begin{array}{l}n=12 \\
100 \% \text { female } \\
12-23 \text { years } \\
\text { AN }<90 \% \text { average }\end{array}$} & \multirow{2}{*}{$\begin{array}{l}\text { "good" or "intermediate" MRS, } \\
\text { modified to include a minimum } \\
\text { weight gain of } 4 \mathrm{~kg} \text { and body weight } \\
\text { within } 10 \% \text { of } 50^{\text {th }} \text { percentile of BMI }\end{array}$} & Family-Based Treatment (FBT) & 58 \\
\hline & & & FBT (6 months) & 58 \\
\hline
\end{tabular}

This article is protected by copyright. All rights reserved. 


\begin{tabular}{|c|c|c|c|c|}
\hline & body weight & & & \\
\hline \multirow{4}{*}{$\begin{array}{l}\text { Lock et al. } \\
2005 \& \\
\text { Lock et al. } \\
2006\end{array}$} & \multirow{4}{*}{$\begin{array}{l}N=86 \\
90 \% \text { female } \\
12-18 \text { years }\end{array}$} & $\mathrm{BMI}>17.5$ & FBT, short or long-term & 96 \\
\hline & & $\begin{array}{l}\text { BMI > } 20 \text { and Eating Disorder } \\
\text { Examination (EDE) within } 2 \text { SDs of } \\
\text { community norms }\end{array}$ & FBT, short or long-term & 67 \\
\hline & & $>90 \% \mathrm{IBW}$ & FBT, short or long-term (4 years) & 89 \\
\hline & & EDE within adult community norms & FBT, short or long-term (4 years) & 74 \\
\hline
\end{tabular}

\begin{tabular}{|c|c|c|c|c|}
\hline Study & $\begin{array}{c}\text { Sample } \\
\text { Characteristics }\end{array}$ & Definition of Remission & Treatment Component & \% Remitted \\
\hline \multirow{2}{*}{$\begin{array}{l}\text { Lock et al. } \\
2010 \& \\
\text { Le Grange et } \\
\text { al. } 2014\end{array}$} & \multirow{2}{*}{$\begin{array}{l}n=61 \\
89 \% \text { female } \\
12-18 \text { years }\end{array}$} & \multirow{2}{*}{$\begin{array}{l}\geq 95 \% \text { Expected Body Weight (EBW) } \\
\text { and EDE Global within } \\
1 \text { SD of community norms }\end{array}$} & FBT & 43 \\
\hline & & & FBT (4 years) & 28 \\
\hline \multirow{2}{*}{$\begin{array}{l}\text { Agras et al. } \\
2014\end{array}$} & \multirow{2}{*}{$\begin{array}{l}n=78 \\
86 \% \text { female } \\
12-18 \text { years }\end{array}$} & \multirow[t]{2}{*}{$\geq 95 \% \mathrm{EBW}$} & FBT & 33 \\
\hline & & & FBT (12 months) & 41 \\
\hline \multirow[t]{4}{*}{$\begin{array}{l}\text { Madden et al. } \\
\text { 2015b }\end{array}$} & \multirow{4}{*}{$\begin{array}{l}N=82 \\
95 \% \text { female } \\
12-18 \text { years }\end{array}$} & \multirow[t]{4}{*}{$\begin{array}{l}>95 \% \text { EBW and EDE Global within } \\
1 \text { SD of community norms }\end{array}$} & $\begin{array}{l}\text { Medical Stabilization (MS), then } \\
\text { FBT }\end{array}$ & 25 \\
\hline & & & MS, then FBT (12 months) & 30 \\
\hline & & & $\begin{array}{l}\text { Weight Restoration (WR), then } \\
\text { FBT }\end{array}$ & 21 \\
\hline & & & WR, then FBT (12 months) & 33 \\
\hline \multirow{2}{*}{$\begin{array}{l}\text { Lock et al. } \\
2015\end{array}$} & \multirow{2}{*}{$\begin{array}{l}N=45 \\
91 \% \text { female }\end{array}$} & \multirow[t]{2}{*}{$\geq 95 \% \mathrm{EBW}$} & FBT & 63 \\
\hline & & & FBT without Intensive Parental & 48 \\
\hline
\end{tabular}

This article is protected by copyright. All rights reserved. 


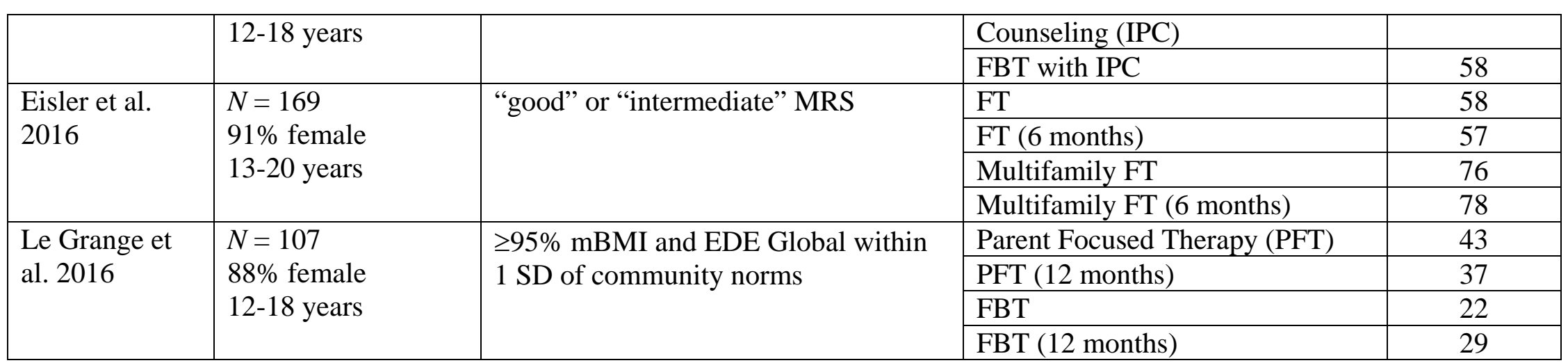

Note. For studies reporting multiple follow-up time points, final row represents last reported follow-up. Data represent the most complete remission rates reported in each study (see original articles for calculation details). AN, anorexia nervosa; MRS, Morgan Russell Scale; FT, family therapy; FC, family counseling; BFST, behavioral family systems therapy; kg, kilograms; BMI, body mass index; FBT, family-based treatment; IBW, ideal body weight; EDE, Eating Disorder Examination; mBMI, median body mass index; SD, standard deviation; EBW, expected body weight; MS, inpatient medical stabilization; WR, inpatient weight restoration; IPC, intensive parental coaching; PFT, parent-focused treatment.

${ }^{a}$ This report describes the stratified subgroup of AN with onset before 18 years of age and duration of illness less than three years, which yielded a primarily adolescent sample $(M=16.6$ years old, $S D=1.7)$. Other AN subgroups in this study extended to older individuals (Subgroup $2 M=20.6$ years old, $S D=4.0$; Subgroup $3 M=27.7$ years old, $S D=7.8$ ) by virtue of age of onset and/or duration of illness. Please see original study for further details.

${ }^{\mathrm{b}}$ Although the original study did not report the frequency or percent remitted, these data were later reported in a meta-analysis. ${ }^{4}$ 
Table 2: Definitions of remission and Results of these Definitions applied to data from a clinical trial of two interventions for anorexia nervosa.

\begin{tabular}{|l|l|c|}
\hline & Definition of Remission & Results (\% remitted) per Definition \\
\hline 1. & BMI $>17.5$ & 76 \\
\hline 2. & BMI $\geq 25^{\text {th }}$ percentile for age & \multicolumn{1}{|c|}{59} \\
\hline 3. & BMI $\geq 50^{\text {th }}$ percentile for age & 22 \\
\hline 4. & $\begin{array}{l}\geq 85 \% \text { mBMI with bulimic symptoms occurring less than once } \\
\text { per week over the past month (equivalent of “good” or } \\
\text { "intermediate” MRS) }\end{array}$ & 76 \\
\hline 5. & $\geq 85 \%$ mBMI & 61 \\
\hline 6. & $\geq 90 \%$ mBMI & 43 \\
\hline 7. & $\geq 95 \%$ mBMI & 88 \\
\hline 8. & EDE Global within 2 SDs of norms & 77 \\
\hline 9. & EDE Global within 1 SD of norms & 38 \\
\hline 10. & $\geq 95 \%$ mBMI plus EDE Global within 2 SDs of norms & 32 \\
\hline 11. & $\geq 95 \%$ mBMI plus EDE Global within 1 SD of norms & \\
\hline
\end{tabular}

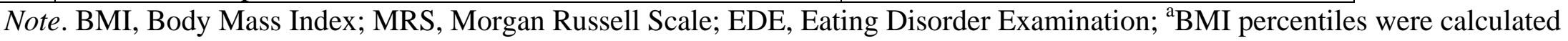
using the Centers for Disease Control and Prevention for age and gender formula, available at

https://nccd.cdc.gov/dnpabmi/calculator.aspx 
Figure 1. Comparison of remission rates in a clinical trial of interventions for anorexia nervosa based on different definitions of remission.

Note. BMI, body mass index; EDE, Eating Disorders Examination; mBMI, median body mass index; SD, standard deviation. 


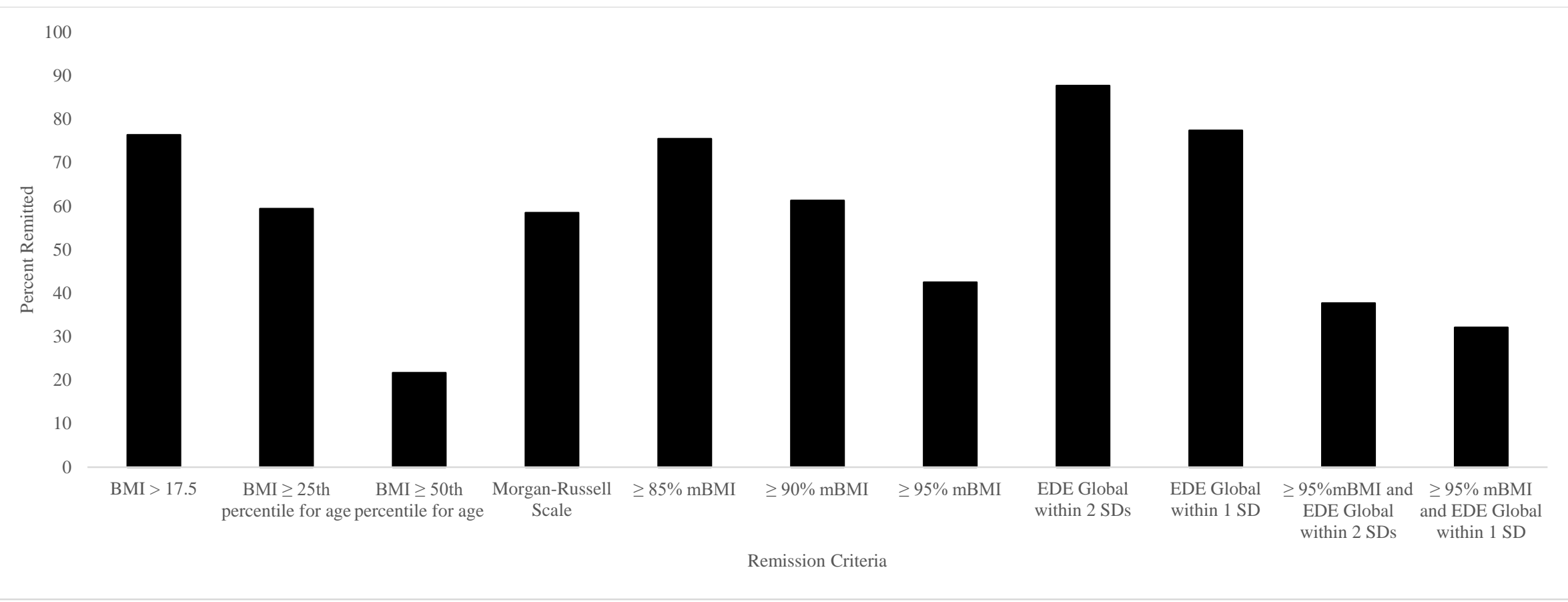




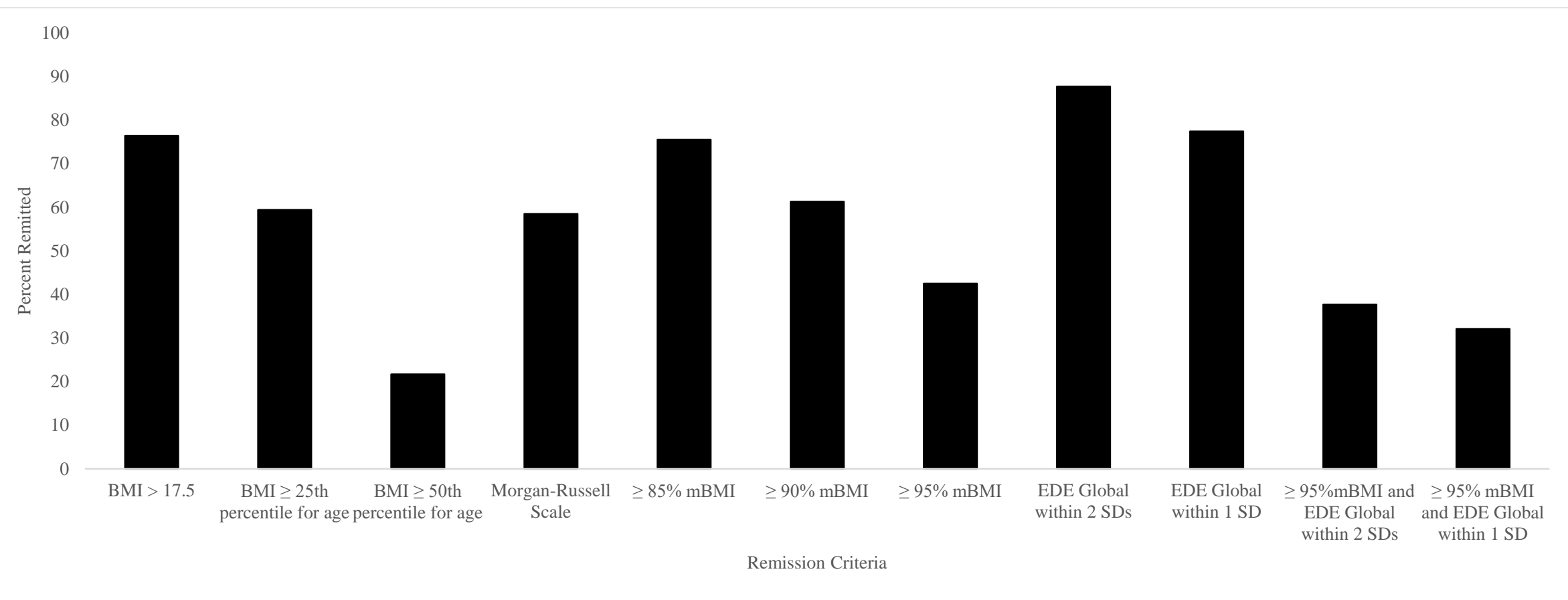

This article is protected by copyright. All rights reserved. 


\section{University Library}

\section{- M M N E R VA A gateway to Melbourne's research publications}

Minerva Access is the Institutional Repository of The University of Melbourne

Author/s:

Le Grange, D;Huryk, KM;Murray, SB;Hughes, EK;Sawyer, SM;Loeb, KL

Title:

Variability in remission in family therapy for anorexia nervosa

Date:

2019-07-18

Citation:

Le Grange, D., Huryk, K. M., Murray, S. B., Hughes, E. K., Sawyer, S. M. \& Loeb, K. L. (2019). Variability in remission in family therapy for anorexia nervosa. INTERNATIONAL JOURNAL OF EATING DISORDERS, 52 (9), pp.996-1003. https://doi.org/10.1002/eat.23138.

Persistent Link:

http://hdl.handle.net/11343/286161 